\title{
La capilla del Hospital de Santiago en Úbeda a través del estudio tridimensional de su sección
}

\author{
Antonio Estepa Rubio | Universidad San Jorge \\ Jesús Estepa Rubio | ER arquitectos \\ Javier León Torres | Investigador independiente \\ Url de la contribución: <www.iaph.es/revistaph/index.php/revistaph/article/view/4822>
}

\section{RESUMEN}

Presentamos, en este artículo, una revisión de la propuesta de Vandelvira para la capilla del Hospital de Santiago en Úbeda, entendida como unidad con autonomía suficiente para poder establecer sobre ella un estudio comparado con otras obras de naturaleza sacra, igualmente resueltas por este genial arquitecto.

Las singularidades espaciales, geométricas y constructivas de este fragmento arquitectónico, integrado en un sistema de mayor envergadura formal y funcional, nos permiten generar una reflexión profunda sobre la sistemática proyectual desarrollada por el maestro.

El estudio minucioso de la sección del edificio, en relación con el análisis sobre la morfología de las techumbres, ponen de manifiesto la excepcionalidad de la solución; sobre todo, cuando comprendemos las razones que motivan la disyunción abrupta que se planifica entre las identidades de los espacios interiores y exteriores.

\section{Palabras clave}

Andrés de Vandelvira | Arquitectura | Axonometría | Bóvedas | Estereotomía | Geometría | Hospital de Santiago | Técnica de construcción | Úbeda (Jaén) | Sección | 


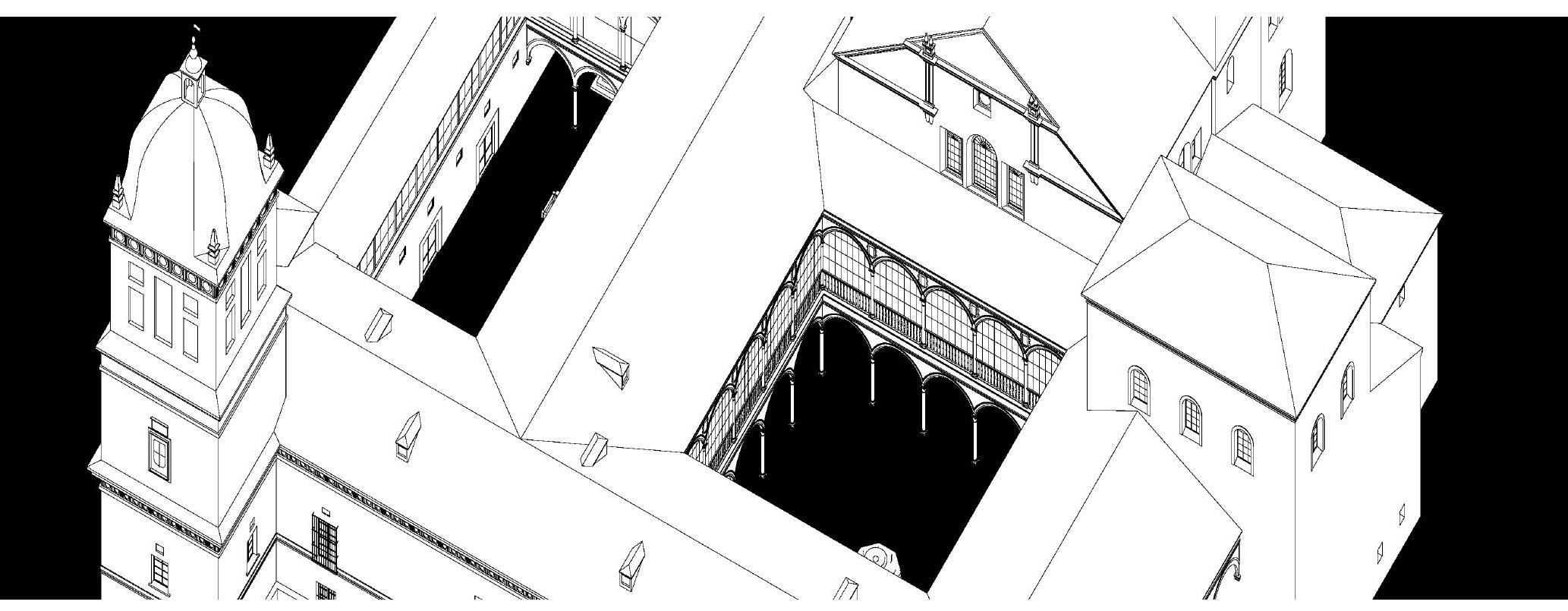

The Santiago Hospital chapel in Úbeda through the volumetric study of its section

\section{ABSTRACT}

We show, in this paper, a review of Vandelvira's proposal for the chapel of the Santiago Hospital in Úbeda, understood as a piece with sufficient autonomy to be able to establish a study on it compared with other works of a sacred nature, also resolved by this great architect.

The spatial, geometric and constructive singularities of this architectural fragment, integrated into a biger formal and functional system, allow us to generate a deep understanding of the design system developed by Vandelvira.

The detailed study of the section of the building, in adition with the analysis of the morphology of the roofs, shows the exceptional nature of the solution; especially when we understand the reasons that motivate the abrupt disjunction that is planned between the identities of the interior and exterior spaces.

\section{Key words}

Andrés de Vandelvira | Arrchitecture | Axonometry | Vaults | Stereotomy | Geometry | Santiago Hospital | Construction technique | Úbeda (Jaén) | Section | 


\section{DISYUNCIÓN EN LA CONFIGURACIÓN INTERIOR DEL ESPACIO SACRO RESPECTO A LA MORFOLOGÍA VOLUMÉTRICA EXTERIOR}

Como sabemos (Guerrero Sánchez 2018, 23-34), en la mayoría de las construcciones sacras del gótico y el Renacimiento español, la constitución volumétrica hacia el exterior de los conjuntos es, a grandes rasgos, una preocupación que deriva de la proclamación de un ideal espacial pretendido desde dentro (Senent Domínguez 2011, 1329-1338).

Están tipológicamente definidos y estudiados muchos modelos arquitectónicos de naturaleza sacra que responden fielmente a contorsiones y figuraciones de carácter espacial, formal, ejecutivo o ambiental (Estepa Rubio y Estepa Rubio, 2018, 164-173); si bien para el caso de la composición exterior resulta evidente que, tan sólo de manera excepcional, se proclama un lenguaje de formalización que tenga capacidad de imponerse a las decisiones que se toman para el espacio de dentro.

Si analizamos alguna de las construcciones paradigmáticas de la historia de la arquitectura universal, entre las que podríamos seleccionar por su trascendencia y su incuestionable valía el templete de San Pietro in Montorio, en Roma, de Bramante, vemos con nitidez que la decisión de priorizar la valoración plástica del exterior implica, por imposición del proyectista, la obligación de reducir las exigencias funcionales del edificio y, en paralelo, la vertebración del empleo de sistemas geométricos mucho más limpios, sencillos y directos.

Así, el modelo de Bramante, manifiesto de un nuevo clasicismo (Benevolo 1972, 364), pretende ser una pieza ejemplar en lo relativo a la composición y a la aceptación de un canon métrico y proporcional ortodoxo; y por ello, según Diego Suárez Quevedo (2003, 316-319), fue concebido bajo una normativización a niveles máximos en busca del dominio y control de los aspectos perspectivos que fueron planeados desde la propia traza del proyecto ${ }^{1}$. El tempietto reduce su contenido y su función en aras de explotar la naturaleza formal que mimosamente se anhela en el tablero de dibujo y finalmente se consigue con la depuración exhaustiva de los trabajos constructivos.

Paralelamente podemos significar, de acuerdo con lo anteriormente dicho, que el tempietto pretende también ensayar un ejercicio de intervención sobre el espacio público; pues a pesar de que este proyecto fuera siempre concebido bajo la clausura de un patio ${ }^{2}$, a su vez integrado en la lógica correspondiente a la totalidad de un edificio, tampoco deja de ser totalmente cierto que el motivo de su erección proclame una conmemoración pública y celebrativa, como se sabe, orientada a honrar el martirio del que fuera el primer pontífice de la Iglesia Católica, señalando, según Benevolo $(1972,369)$, el punto final de la búsqueda proyectual a pequeña escala.

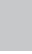


Desde las distancias y las reservas que merece cualquier comparación, podemos enunciar que la lógica discursiva que pretende Andrés de Vandelvira para resolver la configuración del interior del Hospital de Santiago en Úbeda bebe, en parte, de una pretensión de formalización de un encuadre secuencial de sucesos perspectivos y fenomenológicos algo parecidos a los promulgados por Bramante (Estepa Rubio 2017a, 290). Vandelvira proyecta este edificio desde la contestación a demandas públicas y desde la postura de una marcada pretensión por hacer ciudad. Así, la encomienda para dar forma al Hospital de Santiago recae en un ya muy experimentado Vandelvira, por encargo de Diego de los Cobos y Molina (consejero de la Inquisición y obispo de Jaén), sobrino de Francisco de los Cobos, dando luz verde a la puesta en pie de una fábrica que habría de ser significativa y útil para la villa ubetense. La construcción de esta obra se llevó más o menos en paralelo con la del Palacio Vázquez de Molina, concluyendo en el año 1575, coincidiendo así con la muerte del maestro.

El hospital, como otros muchos edificios coetáneos, surge desde la traza de su planta, en donde el patio se torna en la pieza que valida funcionalmente a cada una de las partes que albergan el programa, y en donde se produce

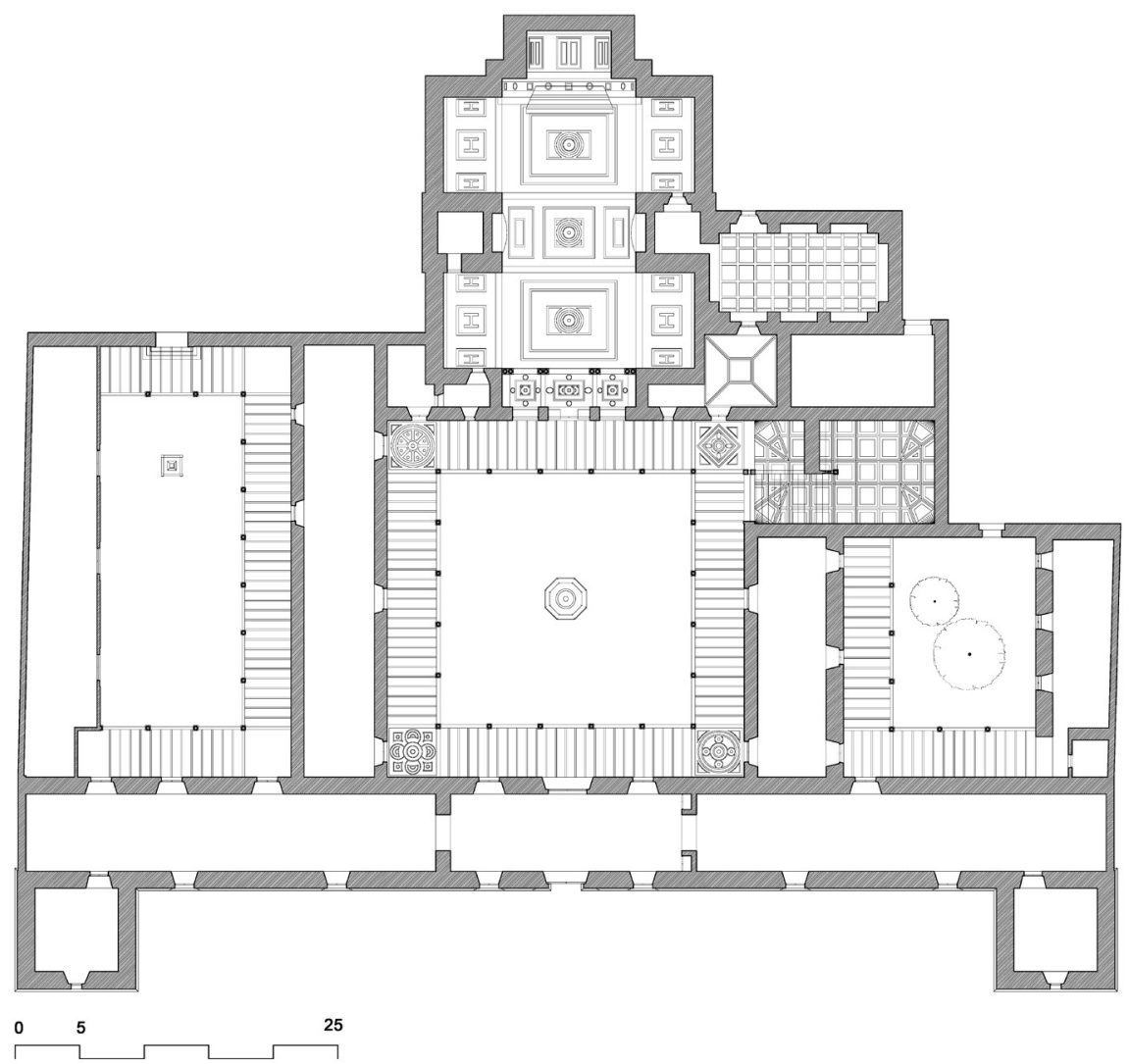

Planta del Hospital del Santiago | plano elaboración propia sobre los levantamientos de Fernando Chueca Goitia 


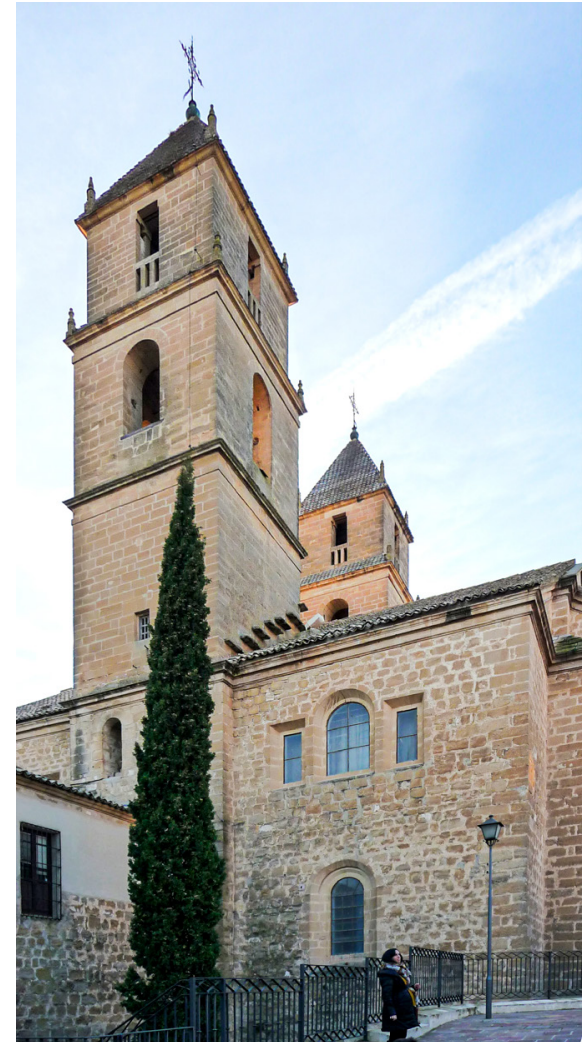

Imagen exterior de las torres y del cuerpo de la capilla | foto Antonio Estepa Rubio

el intercambio natural de flujos con el emplazamiento en donde se enclavan. Por ello, tal y como decíamos para el tempietto, podemos también interpretar que el Hospital tiene una clara vocación de servicio; y por ello, la morfología de su planta se articula desde la premisa de entrelazamiento entre los espacios público y privado. Así, esta interconexión se planificó para que fuera resuelta en un ágora de formalización controlada, en donde la receta arquitectónica parece resolver concienzudamente la transición en la privacidad, a través de una ordenadísima secuencia de umbrales que vienen a tamizar y cualificar la forma en la que se aprehende el edificio.

\section{CRITERIO COMPOSITIVO GLOBAL PARA LA CONFIGURACIÓN DEL CONJUNTO. EL ESPACIO INTERIOR DEL EDIFICIO COMO DISECCIÓN DE LA ATMÓSFERA URBANA}

De acuerdo con la calificación hecha para el patio, y tras la invocación a la figura de Bramante, es importante reseñar que Galera Andreu (2000, 135138) establece también una conexión entre Vandelvira y el maestro italiano a propósito del hospital. Este afortunado parecer se materializa desde la comparativa con el Palazzo dei Tribunali en Roma, en donde efectivamente podemos retratar una organización de la planta a partir de una secuencia homogénea de crujía, patio e iglesia, y en donde la presencia de torres angulares, una amplia fachada y la organización distribuida desde el patio, son evidencia del empleo de un modelo tipológico que se soporta en el anhelo por capturar hacia dentro el espacio registrado de inmediato en la propia ciudad $^{3}$.

Vandelvira resuelve el programa con la disposición de una serie de piezas volumétricas claramente diferenciadas, pues no existen en el hospital espacios de difícil catalogación o dudosa adscripción a una finalidad definida con rotundidad. Los prismas de las torres son identificables desde su arranque hasta su coronación pues, como queda de manifiesto en la planta, penetran notoriamente hacia el interior de la nave de la capilla, protagonizando allí una evidente dislocación del flujo espacial, toda vez que se destruye cualquier perspectiva lineal. la idea de que, como causa de la ausencia rigor en la planificación urbana, se otorgó una importancia mucho mayor a la construcción de las atmósferas del interior de los edificios, en contra de cualquier inversión que satisficiese a las necesidades del espacio público; lo cual no deriva sino de la profunda brecha social que disecciona drásticamente a los distintos estratos que, a priori, podrían llegar a mezclarse en el espacio de la ciudad, sumado al hecho de que, como sabemos, la mayoría de estas edificaciones hubieron de hacerse bajo políticas de mecenazgo.

Significativa resulta la importante ausencia de vestimenta ornamental sobre la totalidad de los paños murales que conforman la estructura del edificio, dado que hay una apuesta en firme por el autismo compositivo global, en pos del empleo del orden arquitectónico como motivo de significación real (Estepa Rubio 2017a, 259). Insistimos, bajo esta consideración, en el hecho de que el edificio disocia con bastante claridad y evidencia la ruptura de las configuraciones ideadas por el arquitecto para el interior con respecto a las de exterior. En todos los espacios del hospital, desde la lonja de acceso al interior de la iglesia, la aparición del orden clásico será siempre ocasional, 
claramente objetual e independiente, sutilmente velada, y, a veces, deformada hasta su desfiguración (Ampliato Briones 1996, 186).

No podemos pasar por alto el hecho de que este encargo llega a Vandelvira en un momento de madurez profesional ${ }^{4}$, en donde ya poco tenía que demostrar sobre su capacidad de abstracción, su ensoñación geométrica y sobre la enorme valía de su inventiva proyectual. Evidentemente la escasez presupuestaria, unida a la celeridad del desarrollo del plan de ejecución de los trabajos, tuvieron que influir de algún modo sobre la manera en la que finalmente el maestro tuvo a bien resolver; sin embargo, lejos de lo que podría parecer, el arquitecto hace de la carencia virtud, llevando así al extremo la depuración conceptual del valor de la estructura como elemento constructor del medio arquitectónico, y en donde la organización de las escalas, entendidas como una alteración en el ritmo de la secuencia vivencial de los espacios del hospital, es empleada como una potente herramienta de cualificación fenomenológica, que nos otorga la capacidad para catalogar a este edificio como una de las obras más radicales del maestro de Alcaraz.

Podemos vislumbrar de un modo ejemplificado el contenido procesual existente en el hospital, entre otros casos, a la hora de estudiar la mecánica de sistematización del acceso al conjunto (García Tapia 1990). El proyectista plantea una llegada al edificio ciertamente no poco ceremoniosa y celebrativa, pues la relación que enhebra entre la lonja que acota el perímetro urbano de la edificación y la larga fachada que se levanta a la Avenida de Cristo Rey resulta ser un importante diafragma que tamiza la manera en la que se accede al edificio, para el cual, la intromisión del escenario urbano hasta sus entrañas adquiere una plusvalía evidente.

Es por eso por lo que Vandelvira adelanta hasta el límite vallado la colocación de cuatro grandes jalones, de tez semejante a los arranques de unos imponentes soportes que son coronados con unas figurillas, y que bien pueden relacionarse con la intención de prolongar la profundidad del trazado de la planta, acotando de un modo rotundo la frontalidad del conjunto, toda vez que se disuelve la presencia del alzado que, como vemos queda más atrás y elevado sobre una escalinata (accesible lateralmente por una rampa). Las cuatro grandes columnas que limitan la lonja aparecen aisladas en el espacio real de la calle, y son reconocibles (a pesar de su deformación) como objetos ficticiamente arrancados del lienzo pétreo trasero, para de forma figurada resolver en serenidad y equilibrio el conjunto de fuerzas liberadas en la composición, y para fijar y estabilizar al mural que introducen (Ampliato Briones 1996, 188).

Si analizamos la magnífica planta trazada por Vandelvira para este hospital, pronto comprenderemos que la lógica de implantación urbana poco tiene que ver con el resto de sus obras más reconocidas (Moreno Mendoza 2005).
4

Resulta llamativo el hecho de que el ocaso profesional de Andrés de Vandelvira quede sellado con la ejecución de una pieza capaz de aunar, en una única traza, el lenguaje experimentado por el arquitecto en sus experiencias en obra civil y en proyectos de naturaleza sacra. Por defecto, podríamos pensar que este hospital forma parte del catálogo de obra civil vandelviriana, si bien sería una torpeza no valorar ni entender la profundidad experimental y propositiva que desarrolla Vandelvira en la solución definida para la capilla. Podemos decir, sin temor a equivocarnos, que la evaluación parcial de la capilla del hospital, con respecto a la totalidad del proyecto, funciona, desde un punto de vista abstracto, como lo hace la Sacristía de la Catedral de Jaén o la ubetense Sacristía de la Capilla de El Salvador. Dicho de otro modo, la capilla ha sido articulada dentro del conjunto con autonomía suficiente como para que podamos entenderla como un proyecto arquitectónico independiente en su evaluación formal, aunque subsidiario en su registro funcional.

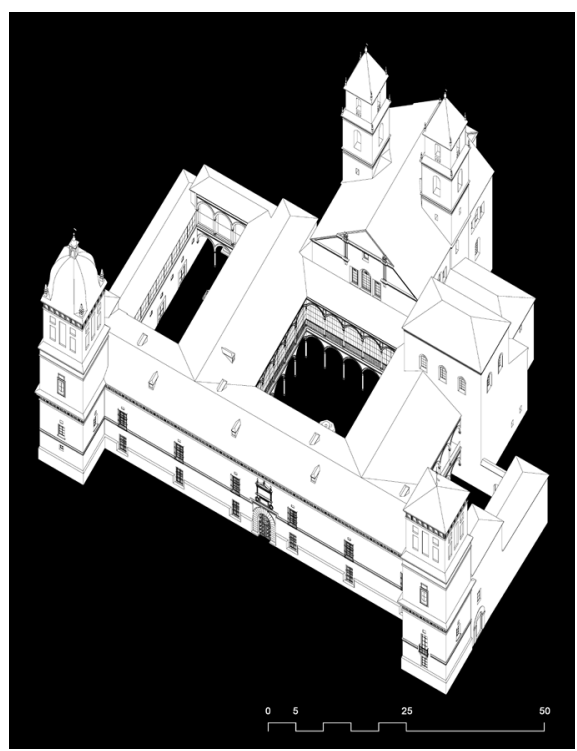

Axonometría militar aérea de la conjunción volumétrica de las distintas piezas que dan forma al Hospital de Santiago. Vista desde la orientación sur | plano elaboración propia 


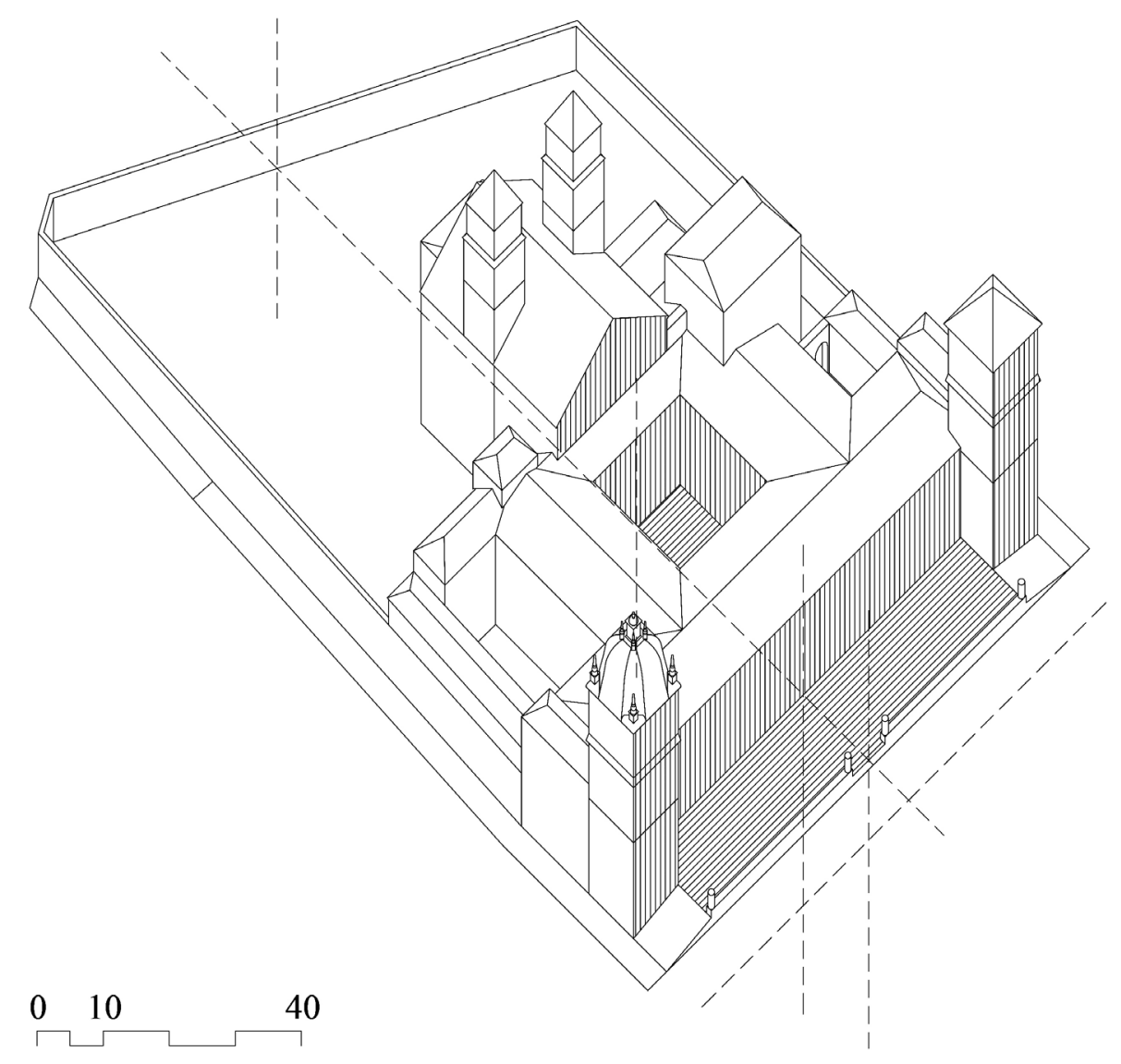

Axonometría militar de la secuencia de acceso al Hospital de Santiago desde el espacio urbano | plano elaboración propia

Esta consideración se comprende especialmente bien en la solución trabajada por Vandelvira y Jamete para la Sacristía de la Capilla de El Salvador de Úbeda. La excelsa sucesión de experiencias plásticas acaecidas en el interior de la sacristía es de imposible reconocimiento al evaluar la anodina imagen que Vandelvira adhiere al edificio proyectado por Diego de Siloé.

Resulta sintomático que en los casos de La Guardia, Huelma, Villacarrillo, o incluso en otras cercanas obras ubetenses, como en la Iglesia de San Nicolás de Bari, el Palacio Vázquez de Molina, Vela de los Cobos o el del Deán Ortega, hace uso de estructuras de configuración formal hacia el exterior muy contenidas, en donde la planificación proyectual se vuelca fundamentalmente hacia dentro. Para estos casos el resultado hacia el exterior es más bien una consecuencia de los sucesos del interior, sobre los que posteriormente, si procede, se impone una organización dérmica a modo de simple aderezo del volumen ${ }^{5}$.

El caso del hospital es totalmente diferente, pues la planta nos presenta una lógica procesual en la organización y en la vertebración de los espacios diametralmente opuesta a la manera en la que se trabaja sobre una estructura compacta, para la cual se resuelven excavaciones volumétricas en el interior. El hospital parece haberse trabajado desde la proclamación de la síntesis aditiva de cada unidad funcional sobre un espacio especialmente engendrado para soportar el proceso, esto es, el gran patio central; que, además de organizar gráficamente la planta, soporta un eje de simetría al 


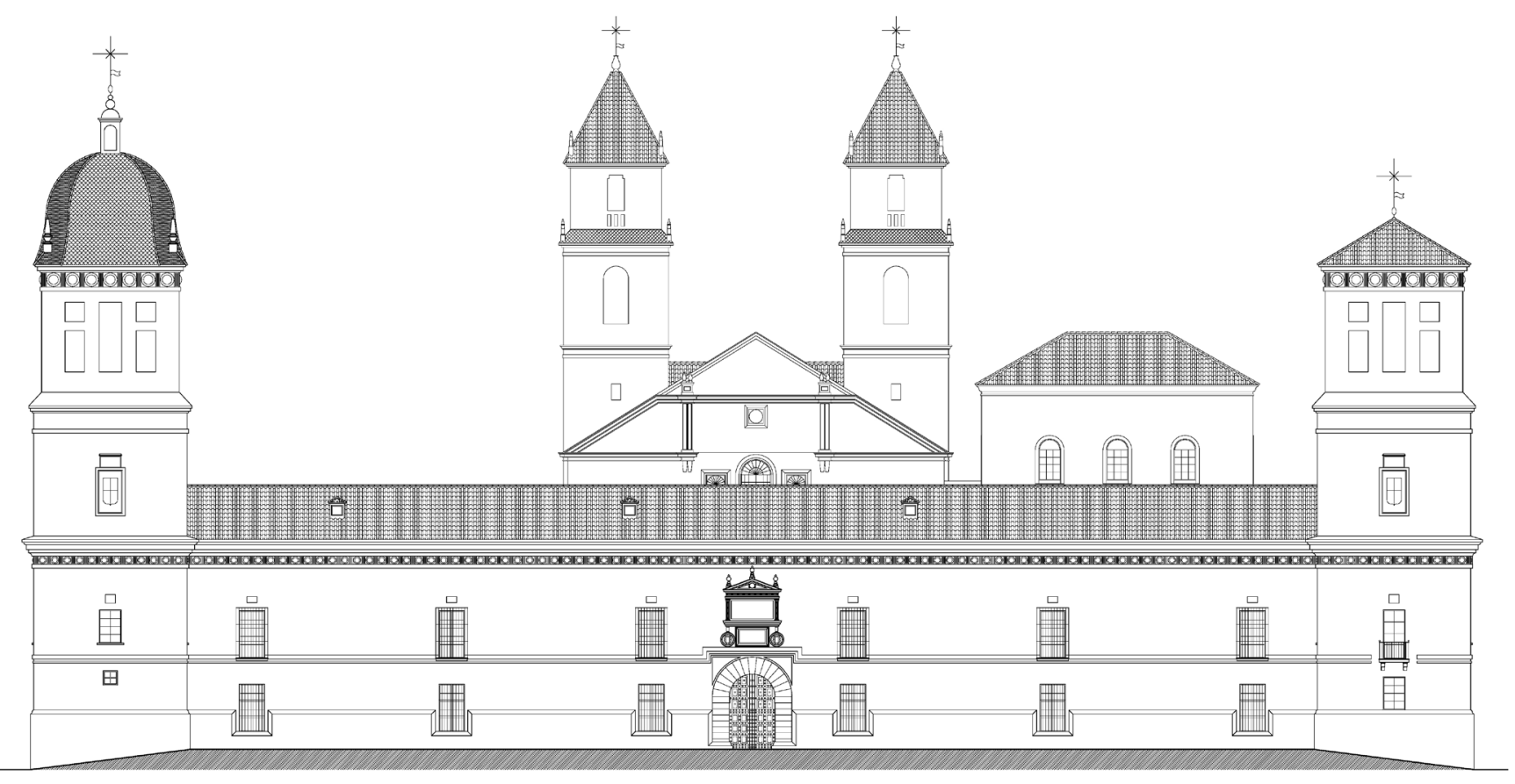

0
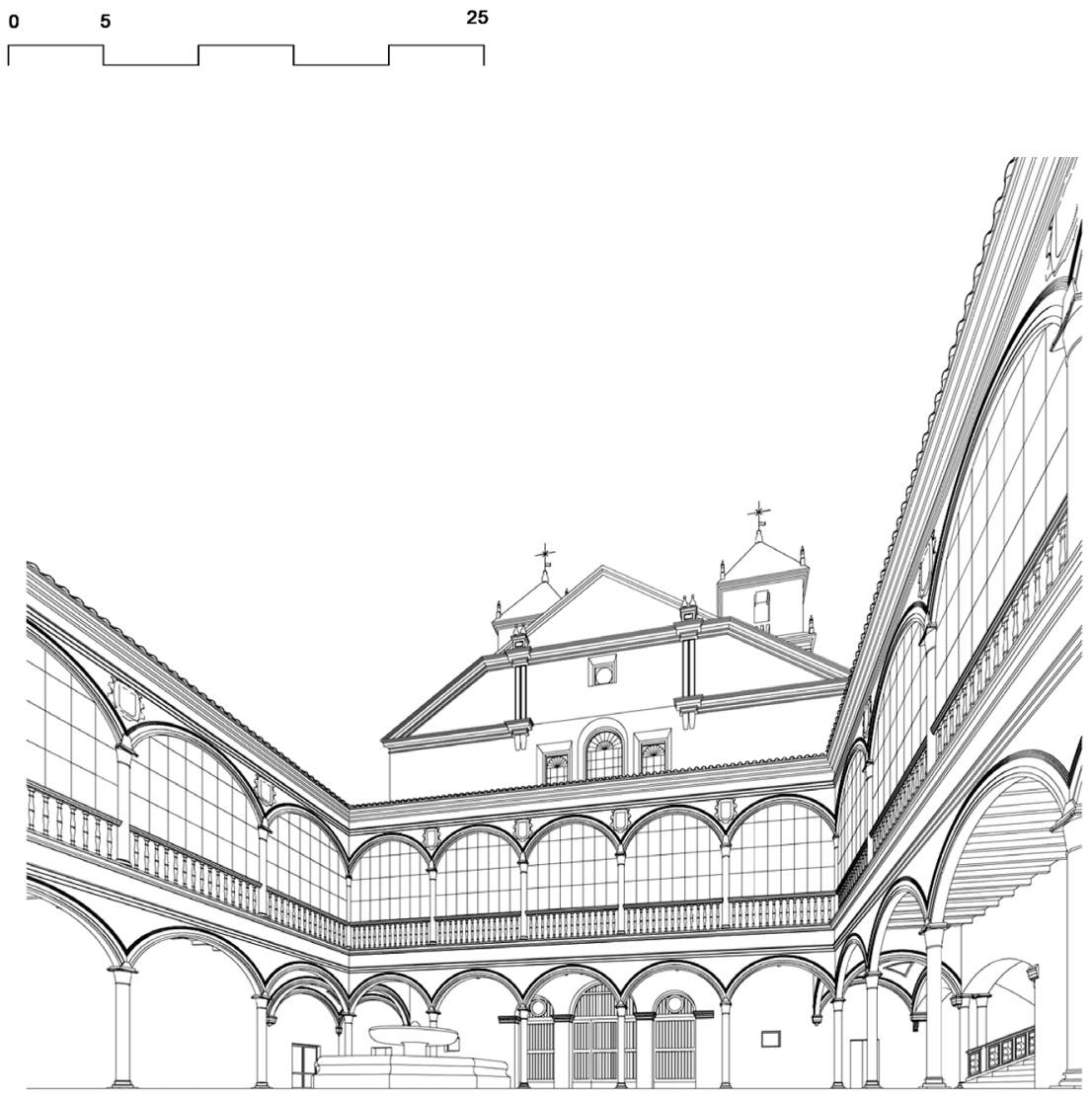

Alzado principal del Hospital del Santiago | plano elaboración propia sobre los levantamientos de Fernando Chueca Goitia 
que linealmente quedan magnetizados cada uno de los fragmentos volumétricos que materializan la edificación.

El patio puede entenderse como una veladura semiconstruida donde se adhieren edificaciones resueltas con absoluta autonomía, pues ya la primera de las piezas, la que se manifiesta con más rotundidad sobre la escena urbana, toma la decisión unilateral de enfrentarse ortogonalmente al eje de la composición, manifestando una dislocación volumétrica que es llevada al extremo cuando Vandelvira además decide disociar de esta gran nave las dos torres levantadas hacia la Avenida de Cristo Rey. Por eso el patio es un espacio acogedor y tranquilo, ideado bajo la presunción de ser un elemento de restitución formal, donde, de manera análoga a lo que sucede en
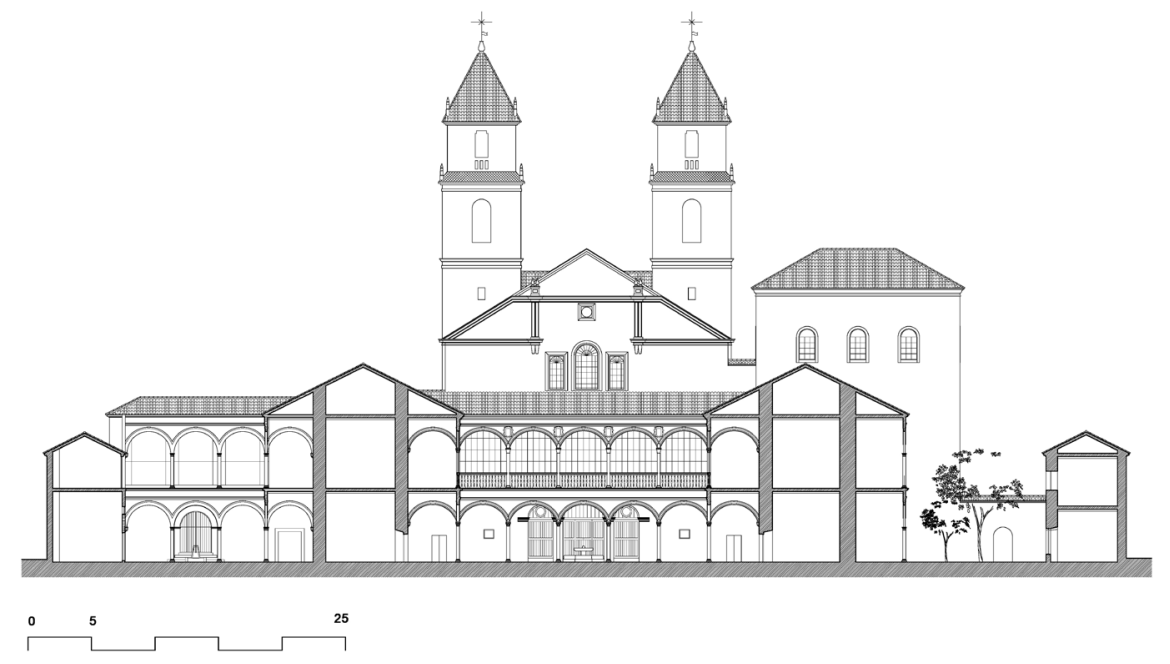

Arriba, sección transversal por el patio principal de Hospital del Santiago; abajo, sección longitudinal por el patio principal y la capilla del Hospital del Santiago | planos elaboración propia sobre los levantamientos de Fernando Chueca Goitia

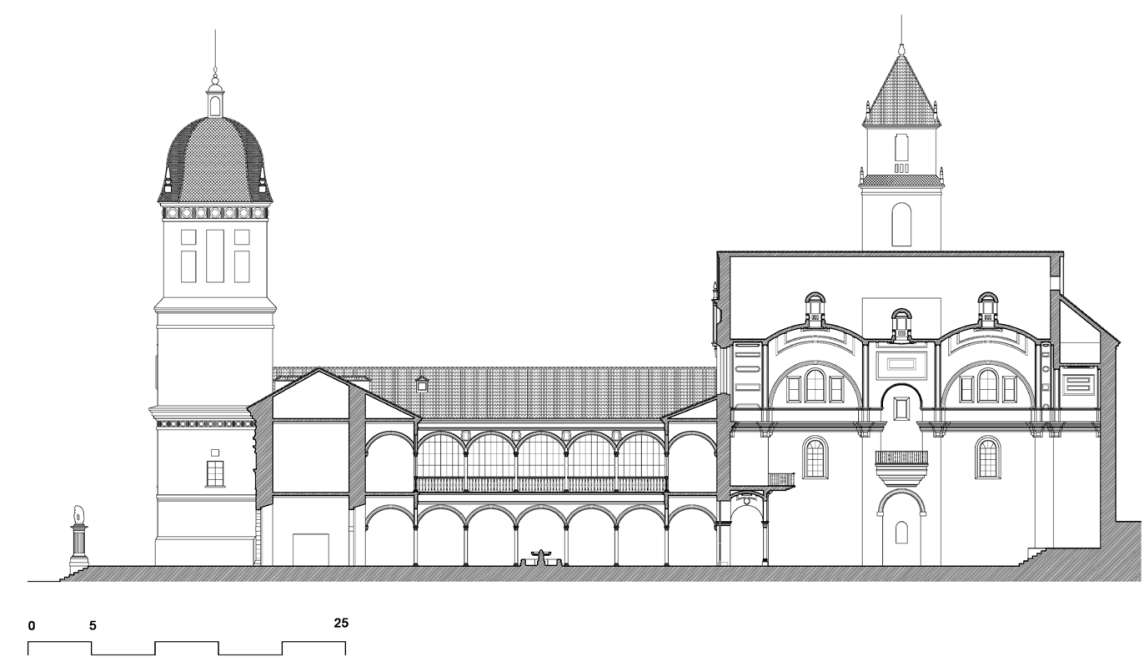




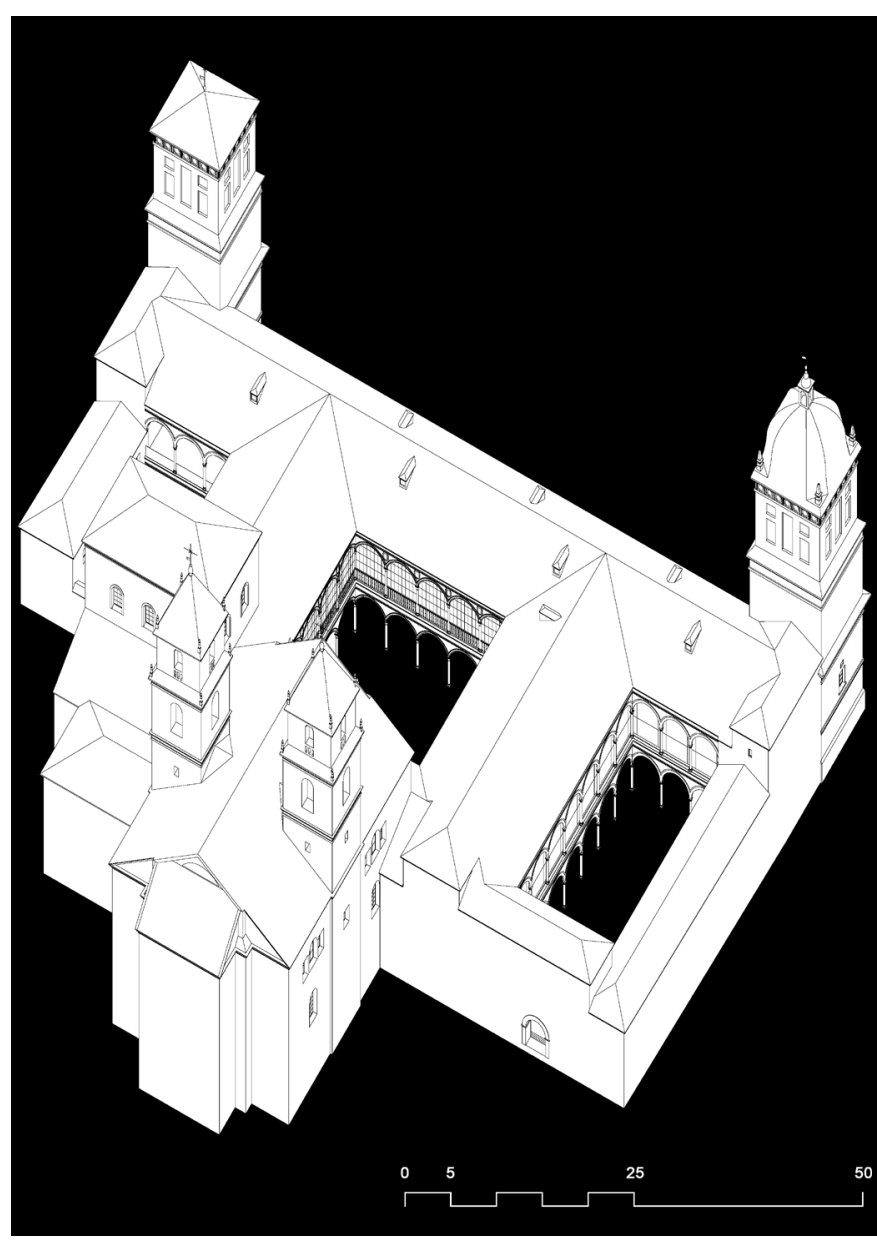

el Palacio Vázquez de Molina, fomenta unas condiciones de aprehensión perspectiva y de gradación de los ambientes.

La fragilidad de este patio no es sólo efecto de la elección de un determinado sistema de proporciones para su orden arquitectónico, sino que ésta se manifiesta a través de la imposición de una serie de elecciones que hacen de él un delicado espacio lleno de matices y de sugerencias; como, por ejemplo, sucede con la imposición de un doble nivel de arcos rebajados, que parecen querer menguar la altura del mismo, la imposición de una clara diferenciación cromática para los soportes, que se manifiestan orgánicamente como separados de los muros traseros o, por supuesto, la aparición de la robusta balaustrada que da forma al antepecho del nivel superior del patio que, tal y como sucede para el Palacio Vázquez de Molina ${ }^{6}$, posibilita un desenfoque de la transparencia del nivel superior, entre otras cosas, bajo la intención de solidificar la comunión del nivel inferior del patio con el discurso natural de funcionamiento de la lonja del hospital y, por añadidura, del tejido urbano. 
liberado y visualmente despejado desde el mismo instante en el que se accede al edificio.

\section{7}

Téngase en cuenta la importante luz que salva la escalera, lo que hace que la bóveda que se suspende sobre ella funcione como una membrana que descarga sus esfuerzos sobre la caja mural que confina este imponente espacio. Igualmente, al ver la escalera con detenimiento, cabría resaltar la elegancia con la que Vandelvira acorta los tramos estructurales en las zonas de arranque y fin de la misma, en este caso, a partir de la intromisión de un par de pilares adintelados sobre los que Vandelvira inventa unos arcos en esviaje (arco avanzado a regla según el tratado redactado por su hijo Alonso), signo inequívoco de su inventiva proyectual y de sus abrumadores conocimientos del arte complejo de la estereotomía y de los secretos de la geometría proyectiva.

\section{EVALUACIÓN CRÍTICA DE LAS EXPERIENCIAS PLÁSTICAS EN EL INTERIOR DEL EDIFICIO}

Como explica Galera Andreu (2000, 138-139), la escalera del Hospital de Santiago tiene una impronta notable en el conjunto del hospital, aunque ésta sea sólo de dos tramos (no siendo de formato imperial en tres tramos) y no se encuentre situada sobre el eje fundamental que organiza la masa edificada (Martínez Montero 2013, 631-639).

Su importancia y trascendencia se compensa por la amplitud del espacio perteneciente a la gran meseta que la parte $y$, sobre todo, gracias a la imponente altura que le concede el arquitecto; donde dispone una sobresaliente bóveda de amplias dimensiones que nos desvelan, otra vez más, la capacidad de Vandelvira ${ }^{7}$ para manejarse con complicados procesos ejecutivos (Estepa Rubio 2017b, 587-607).

Al llegar a la escalera desde el patio sorprende el tamaño y la altura de las techumbres de la caja mural, en donde el despiece estereotómico (Calvo López y Rabasa Díaz 2016, 67-86) de los paramentos se manifiesta para labrar las aperturas por donde penetra la luz, mientras que, por las proporciones verticales de la escena, parece que la cubrición levita sobre la estancia. A nivel aéreo, la escalera configura un volumen tejado independiente que, por la dimensión de su sección, se separa del resto de la geometría tejada que nace desde el patio, hasta el punto que desde arriba resulta casi inimaginable que esa impronta volumétrica contenga en su interior un programa exclusivamente de función, a priori, marginal y de servicio subsidiario; y que, efectivamente, tan sólo comprendemos y justificamos, si tal y como se ha ido explicando, otorgamos validez a los dos principios fundamentales que enunciamos a continuación. El primero es el hecho de que, en contra de la norma habitual, Vandelvira proyecta esta edificación haciendo primordial el diseño exterior; y el segundo es que este edificio tiene una clarísima vinculación con la escena urbana, sin cuyo contexto no podríamos comprender ni la estructuración de su planta ni el dimensionado de los espacios.

Llegados a este punto, es imprescindible profundizar en el que podría considerarse como el cuerpo más singular de la obra, además de una rarísima variación experimental ensayada por Vandelvira para dar respuesta a un programa sacro; naturalmente toca entonces profundizar en el estudio de la Capilla del Hospital de Santiago pues, en apropiación de las palabra de Chueca Goitia $(1995,212)$, es digna de que se le dedique una atención especial "por la originalidad de su estructura y por la novedad de su arte".

Planificada sobre una traza que responde, como el resto del edificio, a pesquisas arquitectónicas de naturaleza exterior, esta singular capilla recicla algunas de las características espaciales interiores y algunas de las preten- 
siones vivenciales de las estancias que la anteceden. El perímetro interior de la iglesia se corresponde con el contorno abierto del patio, pues ambas circunscripciones se resuelven con un cuadrado de las mismas dimensiones, sobre el cual, para el caso de la capilla, se procede a la manipulación de su contorno a través de dos situaciones. La primera, a partir de la inclusión de los dos cuadrados simétricos que dan lugar a las torres; y la segunda, con la macla de un par de rectángulos que definen el espacio para el ábside y su escalinata. Además, a los contornos de este gran cuadrado superpondrá Vandelvira las estancias anexas, antesacristía y sacristía, que como no podía ser de otra manera volumétricamente son también reconocibles.

El hecho de que Vandelvira defina la capilla con arreglo a las dimensiones del patio abierto se presenta como un síntoma evidente de que otorga a este cuerpo una cualidad funcional por encima del resto de las partes que conforman el hospital. Además, de manera alegórica, el que la dimensión del contorno interior de la iglesia coincida exactamente con la proyección del cielo sobre la planta del edificio podría hacer mención a una mística forma de interrelacionar los aspectos corpóreos de su arquitectura con aquellos aspectos ascéticos y trascendentales propios del programa al que da servicio. Por ello, la conexión entre interior y exterior en esta obra roza lo sublime, pues como muy bien detecta Ampliato Briones (1996, 190), en la sección longitudinal por el eje principal que atraviesa el edificio desde la lonja hasta el ábside de la capilla, se puede observar una correspondencia métrica, inicialmente inapreciable, que hace coincidir el entablamento principal del espacio interior de la iglesia con la cornisa exterior del patio.

Estas dudosamente fortuitas coincidencias formales llevan a Chueca (1995, 207-208) a encontrar un importante parentesco formal del Hospital de Santiago con la magna obra de Juan de Herrera para Felipe II, esto es, el Real Monasterio de El Escorial (Ortega Vidal 1999). Chueca justifica esta valoración en el hecho de que ambos edificios están emparejados por un semejante propósito estético, por su afán de imponer un modelo de organización resuelto por masas de importante magnitud que, a todas luces, poco o muy poco tienen que ver con sus precedentes italianos y que, definitivamente, confirman la capacidad y la autonomía del lenguaje arquitectónico peninsular.

No obstante, aunque la comparación con la obra herreriana, que resulta suficientemente justificada por Chueca Goitia, parece significativamente plausible, hay también que hacer mención a la valiosa yuxtaposición apuntada por Galera Andreu $(2000,133)$, cuando parece ver un importante precedente a esta realización en el Hospital de San Juan Bautista de Toledo, también conocido como Hospital Tavera u Hospital de Fuera, iniciado bajo la supervisión de Alonso de Covarrubias y finalizado bajo las órdenes de Bartolomé Bustamante. La relación con el monumento toledano viene asegurada por la participación de Vandelvira cuando se le encarga una tribuna para la iglesia,

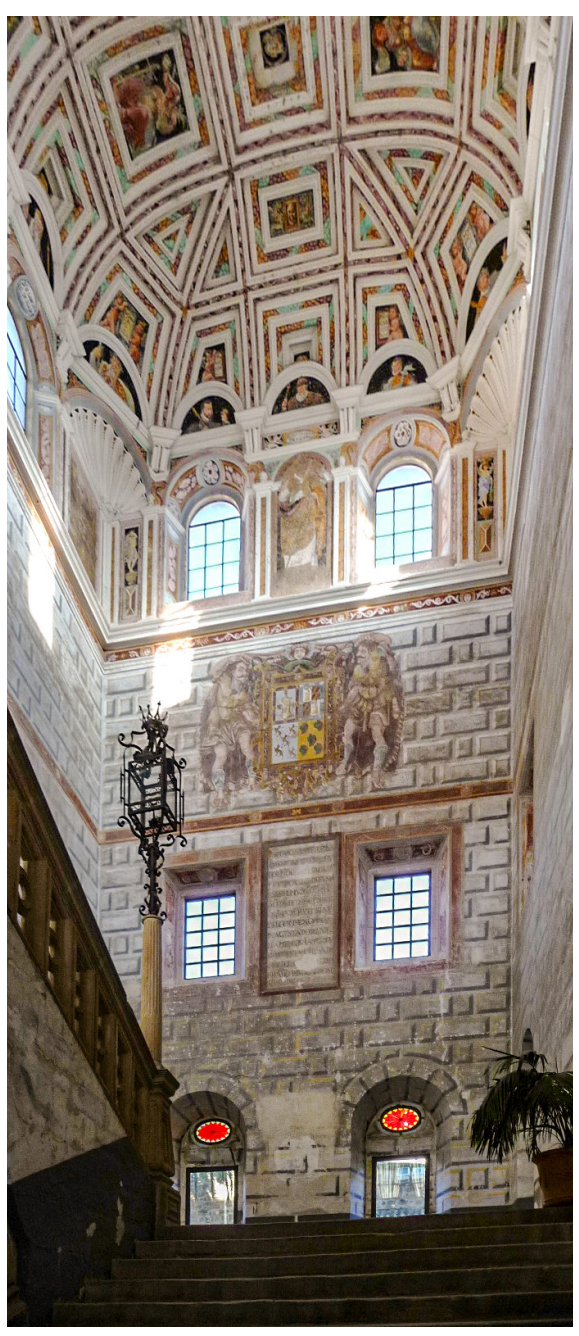

Imagen interior de la caja mural donde se confina la escalera principal del edificio | foto Antonio Estepa Rubio 


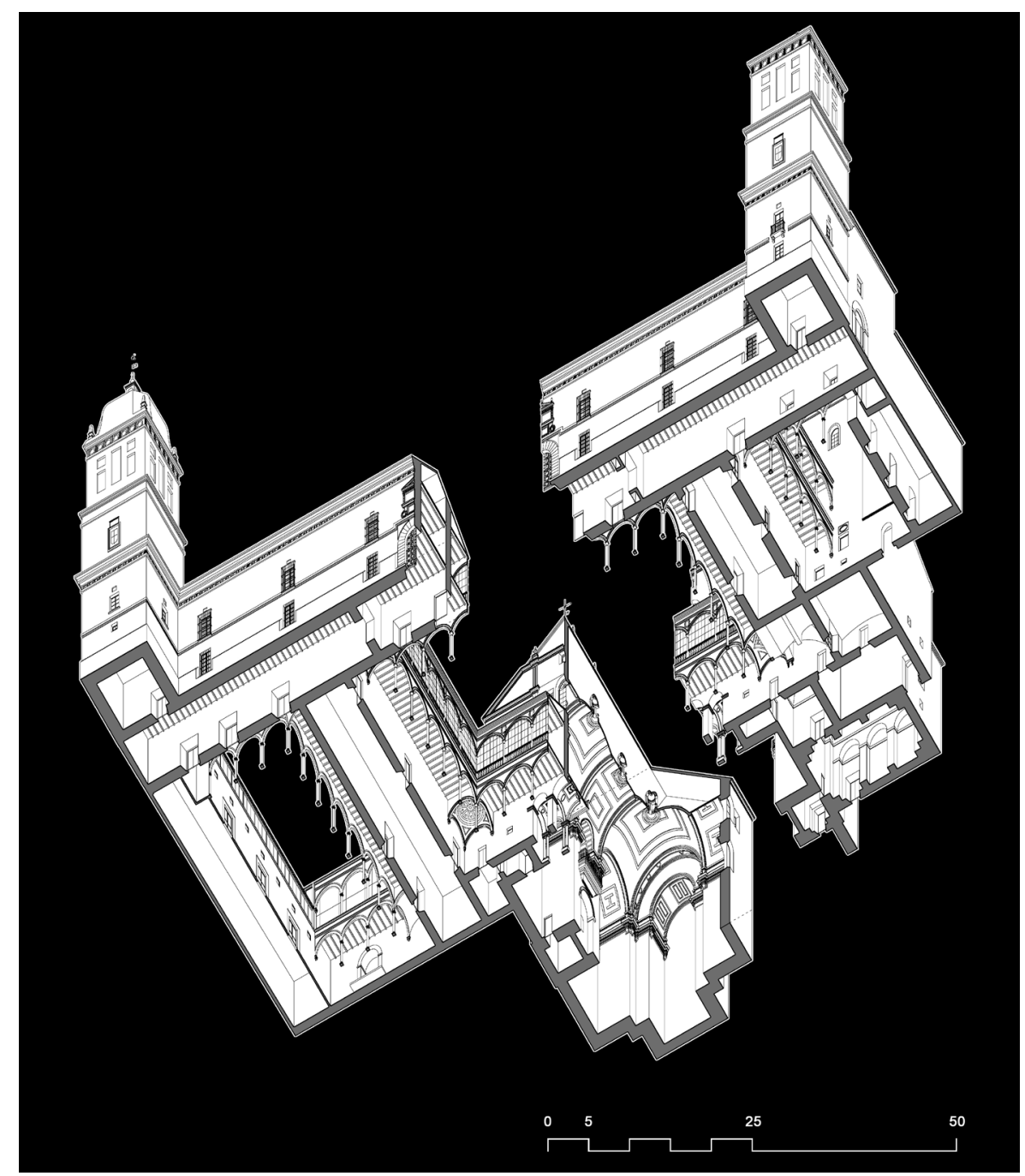

Axonometría militar cenital de la sección longitudinal explosionada por el patio principal y la capilla del Hospital del Santiago. Vista desde la orientación sur | plano elaboración propia

lo que le lleva a visitar este hospital en el momento en el que está desarrollando el proyecto ubetense.

8

No consideraremos esta solución formal, en continuidad con otras investigaciones gráficas resueltas por el profesor Ampliato Briones $(1999,97)$, como parte de un repertorio reglado ensayado por otros arquitectos del momento. Más bien, lo entenderemos como una experiencia plástica donde Vandelvira resuelve, de manera singular, la comunión entre una solución espacial de planta diáfana con un modelo estructural, a priori, limpio y sencillo.

\section{CONDICIONES FORMALES Y VOLUMÉTRICAS DE LA CAPILLA}

Tipológicamente la planta de la capilla responde a un modelo de salón centralizado $^{8}$ (Estepa Rubio 2017a, 206-211), en sustancia parecido (aunque a otra escala) al de la Iglesia Parroquial del Convento de Santo Domingo en La Guardia. En ambos casos Vandelvira ataja la resolución del problema espacial desde la robustez estructural de las cajas murales, eliminando de la escena los soportes aislados y el orden columnario (Sierra Delgado 2009, 166-175), acaso como contestación singular sobre lo aprendido con Siloé, 


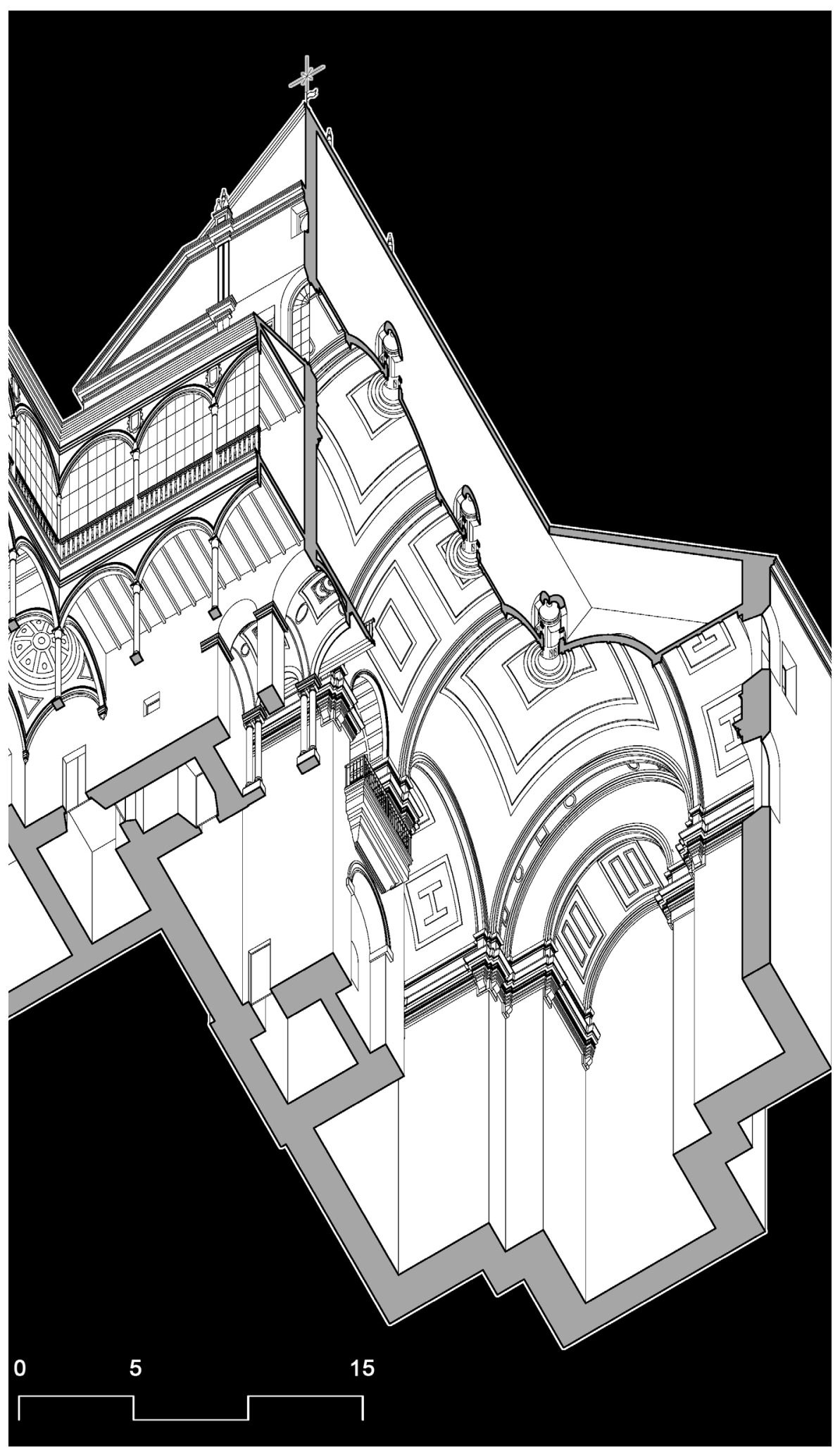

Detalle de la morfología de las techumbres sobre la axonometría militar cenital de la sección longitudinal por la capilla del Hospital del Santiago. Vista desde la orientación sur | plano elaboración propia 
Existen otros casos dentro de la obra de Vandelvira, previos y posteriores, que podrían servir para comprender el porqué de esta solución global, en donde se otorga tanta importancia a la caja mural como solución estructural dominante. Las sacristías de la Catedral de Jaén y la Capilla de El Salvador en úbeda podrían dar sentido a esta tesis, s bien, para reforzar esta idea querríamos referirnos, de manera concreta y precisa, a la solución planteada por el maestro para cubrir la Capilla de los Benavides en Baeza. Pare ese caso Vandelvira desarrolla su "capilla cruzada", en definitiva, una solución aérea que evita el uso de soportes, dibujando atrevida y perspicaz propuesta que, bajo nuestro punto de vista, certifica el interés del arquitecto por el trazado de plantas diáfanas, en donde se cede el protagonismo estructural a los muros que confinan el espacio.

\section{0}

Es evidente que Vandelvira emplea aquí una fórmula de articulación espacial ya ensayada por Siloé en la Sacra Capilla de El Salvador, proyecto sobre el que trabajó en continuidad con el maestro burgalés. La planta de El Salvador está fragmentada, al igual que la que nos ocupa, en dos espacios distintos, esto es, la nave y la cabecera circular. En la traza de Siloé, de manera análoga a la de Vandelvira, aparece la intromisión de dos torres en la charnela de transición entre la geometría rectangular de la nave y la circular de la cabecera, si bien, será a partir de la sección longitudinal desde donde, Siloé por un lado y Vandelvira por otro, permitan la fusión den ambos espacios para generar una identidad volumétrica solidaria y armónica. con lo que se consigue un espacio fluido mayor, y por supuesto, una limpieza rotunda del campo visual.

No obstante, existe un inconveniente que separa estos dos modelos de salón con planta centralizada, pues como no podía ser de otra manera, mientras que en La Guardia tenemos un ensanchamiento del eje transversal al principal de la nave, en el hospital se produce el efecto inverso, es decir, surge un estrechamiento de este mismo eje; objeto de lo cual, las focalizaciones perspectivas para ambos espacios resultan divergentes, a pesar de que a nivel estructural (empleo de la caja mural) e incluso a nivel formal (ausencia de soportes) los principios constitutivos en las dos iglesias coinciden plenamente ${ }^{9}$.

En esta singular capilla las torres asumen un papel hegemónico, pues desde su dialéctica con respecto a otras dos torres más allá del plano de la fachada principal, e inundando la Ionja abierta a la Avenida de Cristo Rey, Vandelvira dispone estos dos hitos, muy significados en altura, para referenciar el volumen más singular de grueso construido. Así, esta decisión, que atiende primordialmente una solicitación de carácter urbano y que posibilita la continuidad del planteamiento arquitectónico global, produce hacia dentro un efecto de constricción que obliga al maestro a volcar sobre el diseño interior su más agudo ingenio y experiencia.

La penetración de estos dos fustes de naturaleza urbana origina una transformación de la planta de salón en una silueta dividida, ahora, en dos espacios bien diferenciados que, sin embargo, gracias al planteamiento de continuidad en su sección verdaderamente funcionan de manera solidaria ${ }^{10}$.

Es evidente que la intromisión de las torres sobre el espacio atrapado por la envolvente mural propicia una distorsión de este vacío volumétrico, si bien cabría considerar una valoración diferente a las que hasta la fecha han resuelto los investigadores que han indagado sobre la decisión de Vandelvira por resolver este problema de tan singular manera.

La justificación bien podría estar fundamentada en una variación sobre nuestra forma de ver la composición de la planta, pues si volvemos a comparar este templo con el de La Guardia, entonces cabría entender que el ábside funcionaría como el famoso ochavo cubierto por una bóveda de Murcia (Alonso Rodríguez y Calvo López 2005, 67-80), según la aplicación de los modelos registrados en el manuscrito de cantería (Calvo et ál. 2010, 519536), a la que se añade un complemento en forma de nave abovedada, lateralmente ampliada, formando una contorno cruciforme al que, para cerrar su geometría y conectarlo con el exterior (para el hospital este efecto lo asumiría el patio), se le acopla una antesala con no mucha más intención que la de alejar y afilar la perspectiva de un solo punto de fuga, coincidiendo, para un caso con el ochavo, y, para el otro, con el ábside. 


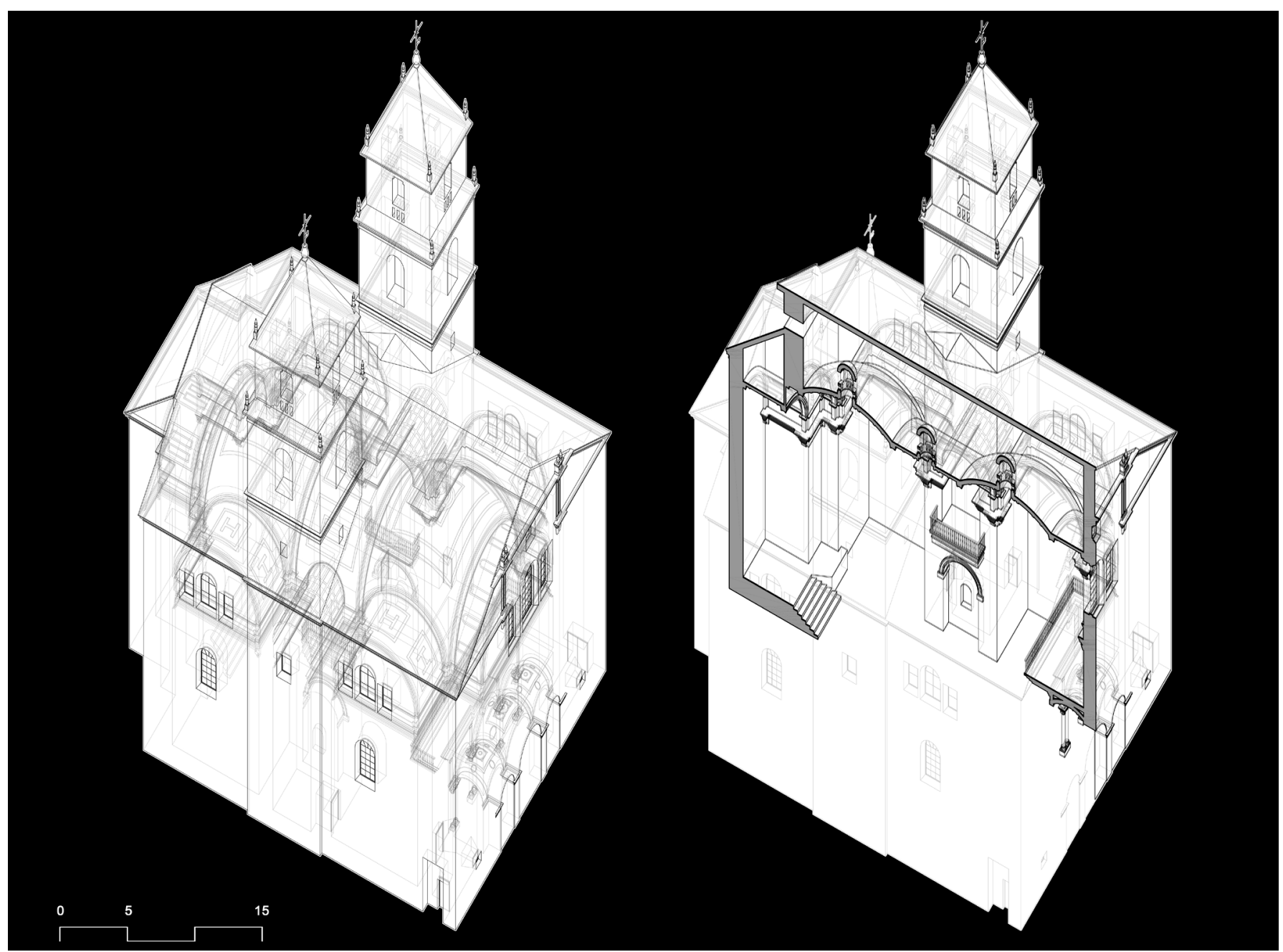

Estudio de la interrelación de las complexiones formales y volumétricas de los espacios interiores

Por eso, no es de extrañar que al interior de la iglesia se acceda desde la galería del patio, ingresando por una gran arco que nos deja bajo el coro, capilla del Hospital del Santiago. Vista desde la orientación este | plano elaboración propia desde donde ya se pueden percibir los tres grandes sistemas de organización aérea que determina el maestro para dar forma al tapamiento horizontal de la estructura mural, y en donde las dos bóvedas baídas que aparecen, antes y después de la bóveda en forma de cañón para el espacio que conecta las dos torres, están dimensionadas en absoluta continuidad.

De esta forma, la transferencia formal y estructural entre las tres superficies se resuelve muy eficazmente con el empleo de un par de curvas de intersección que quedan contenidas de una manera pulcra y elegante entre la primera baída y el cañón, y el cañón y la segunda baída. Para completar el tapamiento de las dos grandes naves formadas a cada lado de los cuerpos de las torres, simplemente se introdujeron un par de bóvedas de cañón de 
desarrollo ortogonal al cañón principal, con lo cual, se consigue un doble efecto sorprendente: consigue fundir el espacio resuelto por las tres bóvedas principales como si de un único elemento se tratase, mientras que de forma paralela, al introducir los cañones laterales, constituye una secuencia de arcos torales que transforman, casi por arte de magia, la compleja geometría resultante derivada de la intromisión de las dos torres.

Al hilo de lo dicho antes, y como continuación a la evaluación de la transformación de la caja mural a partir de la generación de los arcos torales que subyacen de forzar la transición geométrica entre unas bóvedas y otras, resulta muy pertinente el estudio del alzado del paramento que se observa al dibujar la sección longitudinal del templo. En este sentido, se evidencia que, efectivamente, las torres nunca tuvieron ningún compromiso espacial interior, y hubieron de tratarse como un problema geométrico complejo derivado de una decisión proyectual que atiende a cuestiones del exterior.

Por ello, comprendemos que la entrega de baídas pretende simular el efecto espacial natural de esa misma entrega sobre un soporte; con lo que Vandelvira, entre arco y arco, introduce otro arco que proyecta hasta el fondo (disolviendo casi en su totalidad el efecto de la intromisión de la torre) y enfatiza a través de la disposición de unos gruesos balcones que se asoman hacia dentro.

Así, los arcos formeros del abovedamiento terminan en unos pequeños capiteles colgantes que mantienen una extraña relación con el entablamento

Imagen interior de la secuencia de bóvedas con la que se resuelven las techumbres de la capilla | foto Antonio Estepa Rubio

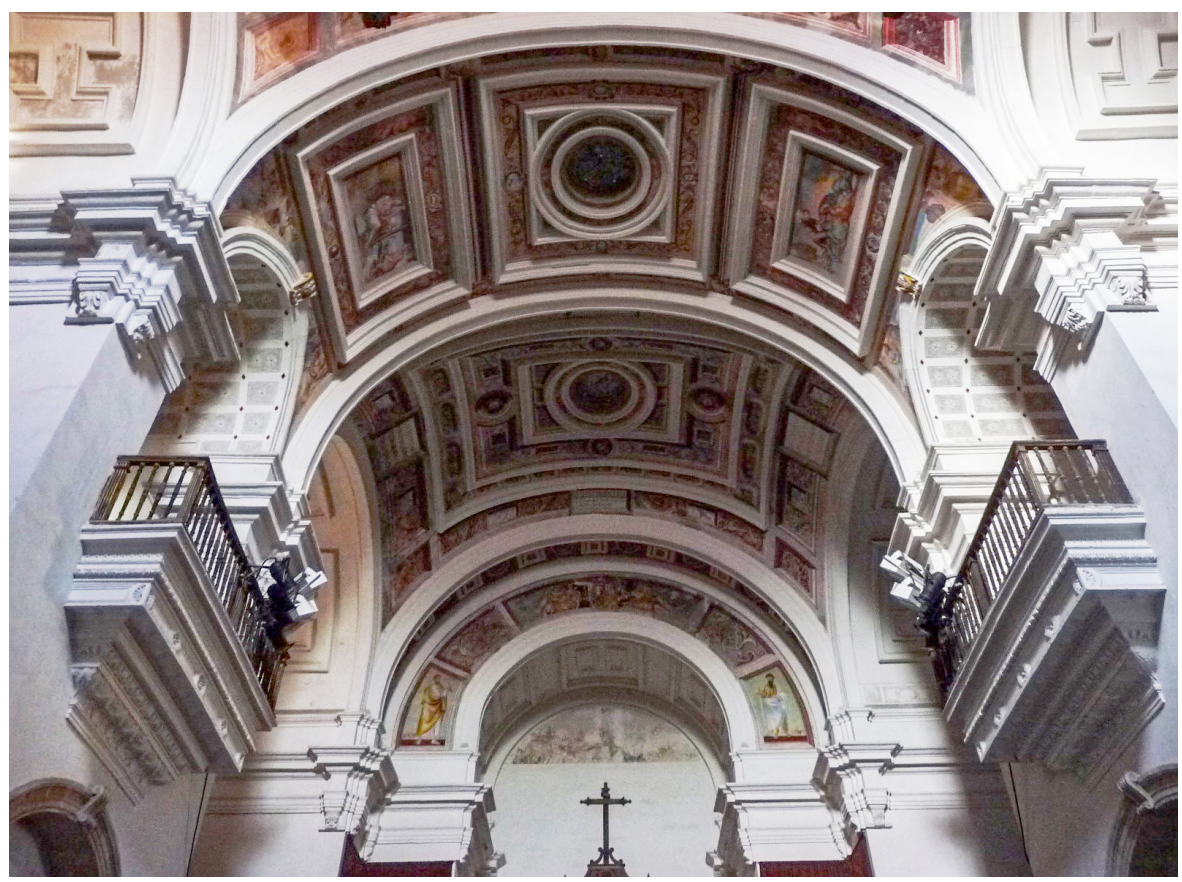


general pues, indiferentes a su trazado, aparecen en aquellos lugares en los que son necesarios para anclar formalmente las bóvedas (Ampliato Briones 1996, 193). El encaje de estas bóvedas con los lienzos pétreos estructurales vuelve a recordarnos la solución empleada por el maestro en La Guardia, puesto que allí también se deja constancia de la transformación de la cubierta ingrávida de las superficies abovedadas contra los muros, a partir del empotramiento contra el lienzo de un par de semicolumnas corintias, cuya presencia justifica el quiebro sobre sí y el volteado del entablamento que recorre todo el perímetro del templo.

El efecto ejecutivo de la caja mural de la capilla en el Hospital de Santiago es totalmente equivalente al de la Capilla del Convento de Santo Domingo, con la salvedad de que intencionadamente se elude la aparición de ningún tipo de soporte, dando validez al registro únicamente a partir de los quiebros en forma de ménsula diseñados para resolver las angulaciones del entablamento en los puntos donde se hace efectiva la entrega de los arcos formeros. Las bóvedas se mantienen así en un universo propio e ingrávido (Palacios Gonzalo 1987, 54-65), por encima de la organización mural, evocando más la forma soplada de un pañuelo que una estructura gravitatoria.

Por otro lado, volviendo al empleo hermenéutico del análisis comparado, llega a ser también reveladora la conexión funcional del arco central de la capilla del hospital y del arco que acuerda la transición entre los dos sistemas de envolvente mural proyectados por Siloé y construidos por Vandelvira para la Sacra Capilla de El Salvador. Parece evidente que la magistral solución que el maestro plantea para el hospital no fue objeto del azar, pues tal y como sucede en la Sacra Capilla, el arco de transición que propicia el difícil encuentro entre el muro curvo y la caja de la nave principal se puede entender como un hábil diafragma que permite un encuentro limpio entre geometrías complejas; solución conceptualmente similar a la empleada en la capilla del hospital, con la diferencia de que mientras en una capilla la transición se propicia entre un contorno rectangular y otro circular, en la otra iglesia la transición se practica entre un contorno rectangular con otro equivalente, por lo que para el caso del hospital, la solución es cualitativamente más reconocible (Estepa Rubio 2017a, 268-269).

Según Ampliato Briones (1996, 194), en ese último y radical ejercicio, Vandelvira conecta principio y final de una obra extremadamente coherente, marcada por una profunda y permanente revisión de todos los fundamentos teóricos de la arquitectura de su tiempo. Por su parte, Galera Andreu (2000, 142) afirma que esta iglesia destaca como un último ensayo de espacio sacro, bastante ajeno a lo realizado hasta entonces, en donde han desaparecido los soportes cruciformes de corte siloesco para abordar el modelado interior de una enorme masa y una caja rectangular con su cabecera destacada, a partir del empleo de recursos fieles a su característico estilo. 


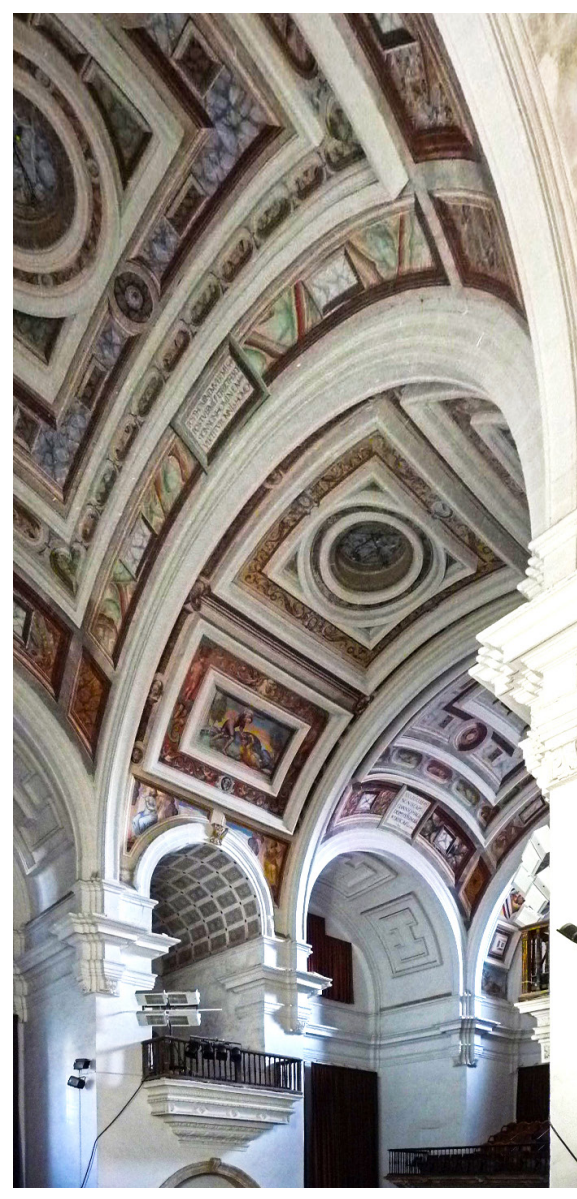

Detalle de la solución de acuerdo de la caja mural y las bóvedas en la zona donde se sitúan los cuerpos de las torres | foto Antonio Estepa Rubio

11

El empleo de los nuevos softwares de representación tridimensional que tenemos hoy a nuestro alcance nos permite redefinir, a través del dibujo, detalles formales, estereotómicos y constructivos que ajustan nuevos enfoques sobre el patrimonio histórico-artístico. Así, por la belleza plástica de las soluciones y por la efervescencia de los procedimientos empleados por Vandelvira, parece lógico que se vuelquen miradas renovadas sobre la producción de este arquitecto. El Hospital de Santiago, por la importancia que tiene dentro del catálogo vandelviriano, es uno de los mejores ejemplos para ensayar una revisión crítica y científica sobre su legado. Así, no es sino esto lo que exactamente hemos pretendido en este texto.
El dominio de la desnudez de los paramentos en tres cuartas partes de su altura, contrastada con la concentración de la ornamentación en cornisas y balcones, la evidente diferenciación geométrica de los entablamentos y, sobre todo, el haber conseguido el dominio del flujo espacial circulante, invitan a la reflexión sobre un planteamiento global del espacio (Palacios Gonzalo 2003), y sobre la depuración extrema en la forma de trabajar de un maestro que supo encontrar, en la abstracción compositiva y en la lógica ejecutiva (Palacios Gonzalo 1987, 64), las mejores herramientas con las que contribuyó a la edificación de una de las etapas más gloriosas de la arquitectura española.

\section{CONCLUSIONES}

Como cierre, haciendo una revisión sintética sobre cuanto se ha referido en el texto, queremos referir que el avance de conocimiento que dimana de la revisión gráfica del edificio posibilita comprender, además del pensamiento creativo y compositivo de una arquitecto tan singular como Vandelvira, una lógica de formulación proyectual que, además de estar presente en el Hospital de Santiago de Úbeda, es perfectamente transportable a otras edificaciones del autor, tanto de naturaleza civil como con programación sacra.

No en balde, la genialidad basada en resolver complicados espacios en el interior de cascarones ideados desde fuera, generados a partir del desarrollo de conos según el arte de la montea (Palacios Gonzalo 2003, 16), más allá de ser una muestra sobre el ardor inconformista del momento, pone de manifiesto el espíritu indómito de un maestro con conocimientos técnicos muy avanzados, al menos, a ser comparados con los manejados por sus coetáneos. En este sentido, el artículo que presentamos, fundamentado en el análisis formal a través del dibujo ${ }^{11}$ (Estepa Rubio 2017a, 279), apuesta por una manera hermenéutica de trabajo que, por encima de construir un discurso intelectual más profundo al ya existente, sirve también para generar un potente aparato gráfico con capacidad para profundizar en el valor plástico de su arquitectura.

La visualización axonométrica de las techumbres del Hospital de Santiago, inédita hasta la fecha, nos permite plantear una relectura técnica, a priori, más estricta que la derivada del estudio visual fotográfico. El análisis de la sección longitudinal del edificio, en comunión con la representación axonométrica cenital aquí presentada, evidencia la complejidad, ya no sólo de la ejecución material, sino en esencia, de la articulación espacial existente en tan preciado edificio. 


\section{BIBLIOGRAFÍA}

- Alonso Rodríguez, M.A. y Calvo López, J. (2005) Bóvedas renacentistas de intradós esférico y tórico en el antiguo Obispado de Cartagena. En: Enrique Collado Espejo, P., Lechuga Galindo, M. y Sánchez González M.B. (coord.) XVI Jornadas de Patrimonio Histórico: intervenciones en el patrimonio arquitectónico, arqueológico y etnográfico de la Región de Murcia. Murcia: Gobierno de la Región de Murcia, Servicio de Patrimonio Histórico, pp. 67-80

- Ampliato Briones, A.L. (1996) Muro, orden y espacio en arquitectura del renacimiento andaluz: Teoría y práctica en la Obra de Diego Siloé, Andrés de Vandelvira y Hernán Ruiz. Sevilla: Universidad de Sevilla, Consejería de Obras Públicas y Transportes

- Ampliato Briones, A.L. (1999) El dibujo como instrumento de investigación: Reconstrucción infográfica de ocho templos del manuscrito de arquitectura de Hernán Ruiz II. EGA: revista de expresión gráfica arquitectónica, n. ${ }^{\circ}$ 5, pp. 95-102

- Benevolo, L. (1972) Historia de la arquitectura del Renacimiento. Madrid: Taurus

- Calvo López, J., Molina Gaitán, J.C., Alonso Rodríguez, M.A., López Mozo, A. y Rabasa Díaz, E. (2010) El uso de monteas en los talleres catedralicios: el caso murciano. Semata: Ciencias sociais e humanidades, n. ${ }^{\circ} 22$, pp. 519536

- Calvo López, J. y Rabasa Díaz, E. (2016) Construcción, dibujo y geometría en la transición entre Gótico y Renacimiento. Artigrama: Revista del Departamento de Historia del Arte de la Universidad de Zaragoza, n. ${ }^{\circ} 31$, pp. 67-86

- Chueca Goitia, F. (1995) Andrés de Vandelvira, arquitecto. Jaén: Ed. Riquelme y Vargas

- Estepa Rubio, A. (2017a) Análisis formal del espacio sacro en la obra de Andrés de Vandelvira. Jaén: Colegio Oficial de Arquitectos de Jaén

- Estepa Rubio, A. (2017b) Geometry and construction throug the sacred space of Andrés de Vandelvira. En: Tejedor Cabrera, A. y Molina-Huelva M. (comp.) IDA. Advanced Doctoral Research in Architecture. Sevilla: Universidad de Sevilla, pp. 587-607. Disponible en: https:// idus.us.es/handle/11441/69308 [Consulta: 21/01/2021]

- Estepa Rubio, A. y Estepa Rubio, J. (2018) Figuración y teatralidad en las estructuras de comunicación vertical propuestas por los Vandelvira. Estudio formal y analítico del caracol de emperadores como caso teórico singular. EGA: revista de expresión gráfica arquitectónica, vol. 23, n. ${ }^{\circ} 32$, pp. 164-173. Disponible en: https://doi.org/10.4995/ ega.2018.9809 [Consulta: 21/01/2021]

- Galera Andreu, P.A. (2000) Andrés de Vandelvira. Madrid: Akal
- García Tapia, N. (1990) Ingeniería y arquitectura en el renacimiento español. Valladolid: Secretariado de Publicaciones, Universidad de Salamanca y Caja Salamanca

- Guerrero Sánchez, A. (2018) Fortuna e Historia en el Renacimiento español. Ingenium. Revista Electrónica de Pensamiento Moderno y Metodología en Historia de la Ideas, vol. 12, pp. 23-34. Disponible en: https://revistas. ucm.es/index.php/INGE/article/view/62417 [Consulta: 21/01/2021]

- Martínez Montero, J. (2013) Las escaleras claustrales en la arquitectura nobiliaria del Renacimiento español. En: Huerta Fernández, S. y López Ulloa, F. (ed. lit.) Actas del Octavo Congreso Nacional de Historia de la Construcción: Madrid, 9-12 de octubre de 2013, vol. 2. Madrid: Instituto Juan de Herrera, pp. 631-639

- Moreno Mendoza, A. (2005) La Úbeda de Vandelvira. Sevilla: Fundación José Manuel Lara

- Ortega Vidal, J. (1999) El Escorial: dibujo y lenguaje clásico. Madrid: Sociedad Estatal para la Conmemoración de los Centenarios de Felipe II y Carlos V

- Palacios Gonzalo, J.C. (1987) La estereotomía de la esfera. Arquitectura: Revista del Colegio Oficial de Arquitectos de Madrid, n. ${ }^{\circ}$ 267, pp. 54-65

- Palacios Gonzalo, J.C. (2003) Trazas y cortes de cantería en el renacimiento español. Madrid: Munilla-Lería

- Senent Domínguez, R. (2011) Las bóvedas irregulares del tratado de Vandelvira. Estrategias góticas en cantería renacentista. En: Huerta Fernández, S. (coord.) Actas del Séptimo Congreso Nacional de Historia de la Construcción. Santiago de Compostela, 26-29 octubre 2011, vol. 2. Madrid: Instituto Juan de Herrera, pp. 1329-1338

- Sierra Delgado, R. (2009) De Granada a Úbeda pasando por Verona: Un viaje exploratorio por la forma siloesca de capilla rotonda. EGA: revista de expresión gráfica arquitectónica, n. ${ }^{\circ} 14$, pp. 166-175

- Suárez Quevedo, D. (2003) Donato Bramante, 1502: Tempietto de San Pietro in Montorio (Roma). Anales de Historia, n. ${ }^{\circ}$ 13, pp. 316-319 